\title{
Deciphering the effect of novel bacterial exopolysaccharide-based nanoparticle cream against Propionibacterium acnes
}

\author{
Abraham P. Karlapudi ${ }^{1}$ Vidya P. Kodali ${ }^{2}$ Krishna P. Kota ${ }^{1} \cdot$ Sabiha S. Shaik $^{1}$. \\ N. S. Sampath Kumar ${ }^{1} \cdot$ Vijaya R. Dirisala $^{1}$
}

Received: 22 May 2015/Accepted: 17 August 2015/Published online: 23 January 2016

(c) The Author(s) 2016. This article is published with open access at Springerlink.com

\begin{abstract}
Acne vulgaris (acne) is a chronic inflammatory disease prevalent among adolescents and adults, with significant psychological effects. The aetiology of acne is multifactorial. Several pathophysiological associations have been identified in which Propionibacterium acnes plays a major role. This bacteria primarily affects areas containing oil glands including the face, back and trunk, where it causes the formation of seborrhoea and inflammatory lesions. The treatment methods currently in place have side effects. A novel alternative method with no side effects is hence required. In this study, we report the synthesis of an exopolysaccharide (EPS)-producing bacterialbased nanoparticle as a stable biocompatible material for drug delivery. We then evaluated the effectiveness of EPSbased nanoparticle cream against $P$. acnes. Our results demonstrate that EPS nanoparticles have great potential as a safe and effective topical treatment for acne vulgaris and other associated infections.
\end{abstract}

Keywords Propionibacterium acnes . Acne vulgaris . EPS nanoparticles $\cdot$ Antibacterial activity

Electronic supplementary material The online version of this article (doi:10.1007/s13205-015-0359-5) contains supplementary material, which is available to authorized users.

Vijaya R. Dirisala

drdirisala@gmail.com

1 Department of Biotechnology, Vignan's University, Guntur 522213, AP, India

2 Department of Biotechnology, Vikrama Simhapuri University, Nellore 524003, India

\section{Introduction}

Acne vulgaris (acne) is a chronic inflammatory disease of the sebaceous gland characterized by follicular hyperkeratinization and excessive colonization by Propionibacterium acnes (P. acnes) (Beylot et al. 2014). Acne affects the majority of adolescents, who develop inflammatory lesions such as papules, pustules and nodules, as well as other non-inflammatory lesions (Webster 2014). P. acnes activates immune reactions by releasing chemo-active agents that attract neutrophils, monocytes, lymphocytes, and stimulate the production of pro-inflammatory cytokines (Kistowska et al. 2015). Despite the availability of a number of antibiotics, antibiotic resistant strains of acne are a cause of major global concern (Lomholt and Kilian 2014). In consequence, there have been increased attempts to find a naturally occurring anti-acne agent (Tin and Wiwanitkit 2014). Over the past few decades, exopolysaccharides have gained attention for their bioactive properties such as stability, biodegradability and biocompatibility. In general, exopolysaccharides (EPS) are usually anionic heteropolysaccharides due to the presence of various constituents such as xanthan, alginate and glycans, etc. EPS produced by microorganisms vary in their composition and properties such as anti-bacterial, anticancer, anti-tumoral, anti-ulcer, anti-immune stimulation along with cholesterol-lowering ability (Kumar et al. 2007; Raveendran et al. 2013; Raposo et al. 2014). The mechanism of EPS owing to the antimicrobial activity is attributed to its low degree of polymerization and degree of deacetylation (Poli et al. 2011). EPS penetrates into the cell membrane of the bacteria which in turn interrupts the replication process of bacteria there by suppressing microbial growth (Nwodo et al. 2012). In this study, we synthesized an exopolysaccharide (EPS)-producing 
bacterial-based nanoparticle serving as a stable biocompatible material for drug delivery. We then evaluated the effectiveness of the EPS-based nanoparticle cream's antimicrobial activity against $P$. acnes.

\section{Materials and methods}

\section{Isolation studies of the $P$. acnes strain}

Isolation of $P$. acnes from the human skin was performed using nutrient broth (HiMedia, India) and Trypticase Soy Agar (HiMedia, India) with $5 \%$ sheep blood on petri plates. Different facial samples of $1 \mathrm{~cm}^{2}$ were taken from 22 healthy human volunteers. These were cleansed with a sterile swab and placed in $5 \mathrm{~mL}$ of phosphate buffer saline (Life Technologies, USA). Dilutions were made, and $100 \mu \mathrm{l}$ of each sample was plated then incubated anaerobically at $37{ }^{\circ} \mathrm{C}$ for $48 \mathrm{~h}$. After $48 \mathrm{~h}$ of growth, biochemical tests were performed to determine the presence of $P$. acnes. The reference strain used in our study was $P$. acnes, microbial type culture collection (MTCC) no: 1951. Consent was obtained from patients who took part in this study and all ethical procedures were strictly followed.

\section{EPS extraction}

EPS was extracted from a biofilm-producing Acinetobacter Sea-9 bacterium (Kodali and Sen 2008; Sujana et al. 2013) by centrifuging the overnight bacterium culture at $10,000 \mathrm{rpm}$ for $20 \mathrm{~min}$ at $4{ }^{\circ} \mathrm{C}$ to remove the bacterial cells. The obtained supernatant was collected in a fresh vial and precipitated with two volumes of ice-cold absolute ethanol by incubating the mixture at $4{ }^{\circ} \mathrm{C}$ overnight. The mixture was then centrifuged at $10,000 \mathrm{rpm}$ for $20 \mathrm{~min}$ at $4{ }^{\circ} \mathrm{C}$ the following day. The supernatant was discarded, and the pellet containing EPS was dried at room temperature. It was then dissolved in pure distilled water, and purified for $48 \mathrm{~h}$ by dialysis, using dialysis tubing with a 10,000 molecular weight cut-off. Finally, the purified EPS was freeze-dried, and characterized by Fourier transform infrared spectroscopy [FTIR (Mancuso Nichols et al. 2004)]. The total carbohydrate concentration was determined using phenol-sulphuric acid method (DuBois et al. 1956).

\section{Synthesis of EPS nanoparticles}

As reported previously by others, chitosan molecules undergoing poly-electrolyte complexation with polysaccharides can spontaneously give rise to nanoparticles under strong magnetic stirring (Fotticchia et al. 2014). Various concentrations of EPS solutions were hence mixed with chitosan solution under strong magnetic stirring to form nanoparticles. EPS nanoparticles were prepared by complex formation between EPS and chitosan under strong magnetic stirring. Chitosan was dissolved in $1 \%(\mathrm{w} / \mathrm{v})$ acetic acid to obtain a final strength of $10 \mathrm{mg} / \mathrm{mL}$. EPS concentrations were prepared in distilled water, as well as different solutions with $1-5 \mathrm{mg} / \mathrm{mL}$ concentrations at different pHs. Suspensions of nanoparticles formed spontaneously when chitosan solution was added to EPS solution under strong magnetic stirring at room temperature with varying $\mathrm{pHs}$. Nanoparticle suspensions were filtered and mixed with cream formulation to check the antimicrobial properties (Sivakumar et al. 2014; Sathiyanarayanan et al. 2014).

\section{EPS nanocream formulation}

For the oil phase, $1.85 \mathrm{~g}$ of beeswax was added to $5 \mathrm{~mL}$ of liquid paraffin, followed by a few drops of glycerine. For the aqueous phase, $0.15 \mathrm{~g}$ of borax was added to $3 \mathrm{~mL}$ $\mathrm{DH}_{2} \mathrm{O}$. The cream was obtained by stirring the two phases continuously until they reached $70^{\circ} \mathrm{C}$. The emulsion of EPS nanoparticles and cream was prepared by adding $1 \mathrm{~mL}$ of the EPS solution at different concentrations $(1-5 \mathrm{mg} / \mathrm{mL})$. This was then left overnight to test for stability. The antimicrobial effect of the selected strain was tested using the agar well diffusion method (Bonev et al. 2008).

\section{Results}

\section{Isolation studies of the $P$. acnes strain}

Twenty-two pure colonies were isolated, of which four samples numbered S4, S7, S14 and S19 were screened biochemically to identify the $P$. acnes strain. S19 showed

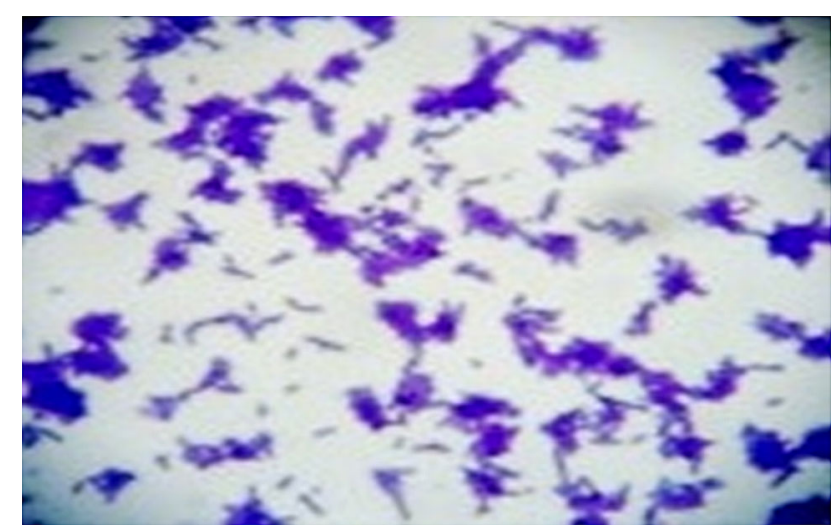

Fig. 1 Gram staining of S19 bacteria. Staining confirmed that S19 is gram positive and rod shaped 
similar biochemical characteristics to reference strain $P$. acnes MTCC 1951 (Fig. 1; Supplementary Table 1).

\section{EPS analysis}

FTIR analysis of extract from Acinetobacter Sea-9 bacterium showed the presence of $-\mathrm{OH}$ band at $3346.62 \mathrm{~cm}^{-1}$ and $\mathrm{COOH}$ groups at $1637.86 \mathrm{~cm}^{-1}$ confirming that the sample was EPS. On chemical analysis using the phenolsulphuric acid method, it was found that the total carbohydrate content in EPS extract was $78 \mu \mathrm{g} / \mathrm{mL}$.

\section{Synthesis of EPS nanoparticles}

The concentration and $\mathrm{pH}$ of chitosan and EPS solutions plays a crucial role in the formation of nanoparticles (Raveendran et al. 2013). Combinations of different $\mathrm{pH}$ were hence evaluated to determine the optimal level for the formation of stable nanoparticles. When the $\mathrm{pH}$ of chitosan solution was in the range of 3, and EPS solution was in the range of 4.5, stable nanoparticles were formed. Gradual increases or decreases in the $\mathrm{pH}$ values of EPS and chitosan solutions outside the above-stated optimal ranges resulted in precipitate formation. Combinations of various concentrations of chitosan and EPS solutions were also analysed for nanoparticle formation. When the concentration of chitosan was $6 \mathrm{mg} / \mathrm{mL}$, and the EPS concentration varied between 1 and $7 \mathrm{mg} / \mathrm{mL}$, an increase in the size of the particles was observed. Large aggregates were formed when the ratio was 6:6. Upon increasing the ratio to $6: 7$, macro-globules formed that were discernible to the naked eye.

\section{Antibacterial activity of the EPS nanoparticles}

The antibacterial activity of EPS nanoparticles against S19 strain was performed by checking varying concentrations. The EPS nanoparticles were effective against $P$. acnes at a concentration of $39 \mu \mathrm{g} / \mathrm{mL}$, and the zone of inhibition was measured as $18 \mathrm{~mm}$ (Fig. 2). Cream with and without chitosan did not show any activity against the organism. After 2 weeks, the EPS nanoparticles were found to be quite stable in a cream emulsion. It was observed that the zone diameter measured for the activity of EPS nanoparticles emulsified in cream was more or less same as that of solitary EPS nanoparticles (18 and $18.5 \mathrm{~mm}$ against S19, respectively). This proves that EPS nanoparticles are stable in emulsions. The antibiotic tetracycline was also effective against the organism, with a zone diameter of $24 \mathrm{~mm}$ (Fig. 2). However, literature suggests that the organism has shown resistance to such antibiotics ( $\mathrm{Si}$ monart et al. 2008; Andriessen and Lynde 2014). A novel

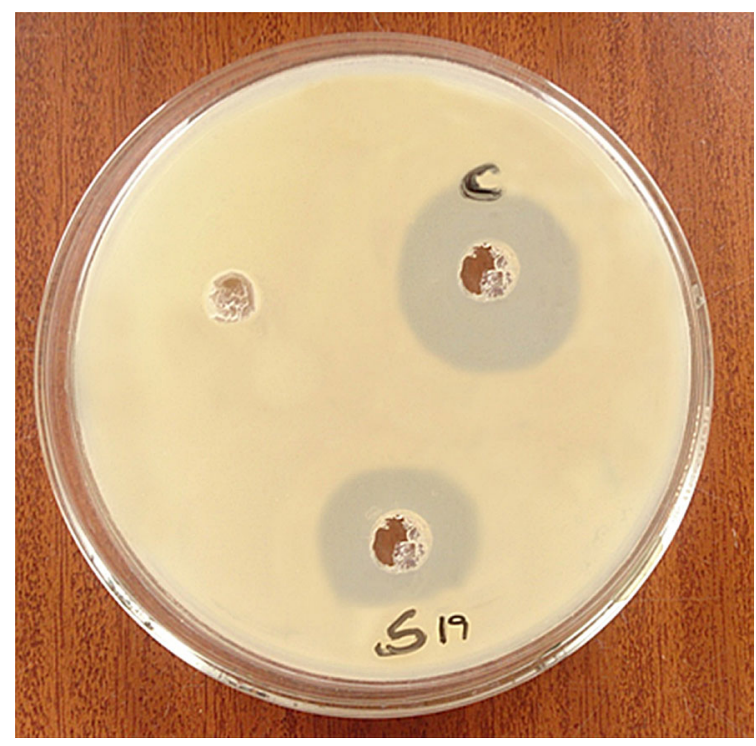

Fig. 2 Antibacterial activity of EPS nanoparticles in cream against sample 19 (S19) at $39 \mu \mathrm{g} / \mathrm{mL}$ concentration [Control (C) - tetracycline]; (no name-chitosan + cream)

treatment should hence involve a substance which is less toxic but more effective.

\section{Discussion}

Acne is a chronic inflammatory disease which is prevalent among adolescents and adults with significant psychological effects (Durai and Nair 2015). Acne-related psychological suffering could be consequently linked to the occurrence of psychiatric disorders such as anxiety, depression, and suicidal ideation (Pace 2014). Standard oral and topical therapies which are being administered are accompanied with side effects such as skin irritation, gastrointestinal upset, and the development of drug-resistant bacteria (Lauren 2014). Research suggests that many patients are vying towards safe alternative therapies for treatment of acne. Considering that exopolysaccharides are accompanied with no side effects (van Bueren et al. 2015), we synthesized and evaluated the effectiveness of EPSbased nanoparticle cream against $P$. acnes. These findings have opened new avenues to explore the significant role of EPS nanoparticles as a safe and effective topical treatment for acne vulgaris and other associated infections.

Acknowledgments The authors thank Vignan's University, India, for providing financial resources to execute this work.

\section{Compliance with ethical standards}

Conflict of interest The authors have no conflict of interest regarding the publication of this paper. 
Open Access This article is distributed under the terms of the Creative Commons Attribution 4.0 International License (http:// creativecommons.org/licenses/by/4.0/), which permits unrestricted use, distribution, and reproduction in any medium, provided you give appropriate credit to the original author(s) and the source, provide a link to the Creative Commons license, and indicate if changes were made.

\section{References}

Andriessen A, Lynde CW (2014) Antibiotic resistance: shifting the paradigm in topical acne treatment. $J$ Drugs Dermatol 13:1358-1364

Beylot C, Auffret N, Poli F, Claudel JP, Leccia MT, Del Giudice, Dreno B (2014) Propionibacterium acnes: an update on its role in the pathogenesis of acne. J Eur Acad Dermatol Venereol 28:271-278

Bonev B, Hooper J, Parisot J (2008) Principles of assessing bacterial susceptibility to antibiotics using the agar diffusion method. J Antimic Chemother 61:1295-1301

DuBois M, Gilles KA, Hamilton JK, Rebers PA, Smith F (1956) Colorimetric method for determination of sugars and related substances. Anal Chem 28:350-356

Durai PCT, Nair DG (2015) Acne vulgaris and quality of life among young adults in south India. Indian J Dermatol 60:33-40

Fotticchia L, Fotticchia T, Mattia CA, Netti PA, Vecchione R, Giancola C (2014) Thermodynamic signature of secondary nanoemulsion formation by isothermal titration calorimetry. Langmuir 30:14427-14433

Kistowska M, Meier B, Proust T, Feldmeyer L, Cozzio A, Kuendig T, Contassot E, French LE (2015) Propionibacterium acnes promotes Th17 and Th17/Th1 responses in acne patients. J Invest Dermatol 135:110-118

Kodali VP, Sen R (2008) Antioxidant and free radical scavenging activities of an exopolysacharide from probiotic bacterium. Biotechnol J 3:245-251

Kumar AS, Mody K, Jha B (2007) Bacterial exopolysaccharides-a perception. J Basic Microbiol 47:103-117

Lauren S (2014) Skin pigmentation disorders: aetiology, assessment and aesthetic treatment options. J Aesthetic Nurs 5:224-229

Lomholt HB, Kilian M (2014) Clonality and anatomic distribution on the skin of antibiotic resistant and sensitive Propionibacterium acnes. Acta Derm Venereol 94:534-538

Mancuso Nichols CA, Garon S, Bowman JP, Raguénès G, Guézennec J (2004) Production of exopolysaccharides by Antarctic marine bacterial isolates. J Appl Microbiol 96:1057-1066
Nwodo UU, Green E, Okoh AI (2012) Bacterial exopolysaccharides: functionality and prospects. Int J Mol Sci 13:14002-14015

Pace JL (2014) The polycystic ovary syndrome and acne. Pathogenesis and treatment of Acne and Rosacea. Springer Berlin Heidelberg, pp 569-577

Poli A, Donato PD, Abbamondi GR, Nicolaus B (2011) Synthesis, production and biotechnological applications of exopolysaccharides and polyhydroxyalkanoates by archaea. Archaea 2011, Article ID: 693253. pp 1-13. doi:10.1155/2011/693253

Raposo DJ, Filomena M, Morais AMMB, Morais RMSC (2014) Influence of sulphate on the composition and antibacterial and antiviral properties of the exopolysaccharide from Porphyridium cruentum. Life Sci 101:56-63

Raveendran S, Poulose AC, Yoshida Y, Maekawa T, Kumar DS (2013) Bacterial exopolysaccharide based nanoparticles for sustained drug delivery, cancer chemotherapy and bioimaging. Carbohydr Polym 91:22-32

Sathiyanarayanan G, Vignesh V, Saibaba G, Vinothkanna A, Dineshkumar K, Viswanathan MB, Selvin J (2014) Synthesis of carbohydrate polymer encrusted gold nanoparticles using bacterial exopolysaccharide: a novel and greener approach. RSC Adv 4:22817-22827

Simonart T, Dramaix M, De Maertelaer V (2008) Efficacy of tetracyclines in the treatment of acne vulgaris: a review. $\mathrm{Br} \mathrm{J}$ Dermatol 158:208-216

Sivakumar B, Aswathy RG, Sreejith R, Nagaoka Y, Iwai S, Suzuki M, Fukuda T, Hasumura T, Yoshida Y, Maekawa T, Sakthikumar DN (2014) Bacterial exopolysaccharide based magnetic nanoparticles: a versatile nanotool for cancer cell imaging, targeted drug delivery and synergistic effect of drug and hyperthermia mediated cancer therapy. J Biomed Nanotechnol 10:885-899

Sujana K, Abraham KP, Mikkili I, Prabhakar KV (2013) Biochemical and molecular characterization of biofilm producing bacteria. Int J Pharm Biosci 4:702-712

Tin SS, Wiwanitkit V (2014) Anti-acne activity of Darchini and Tukhm. Khashkhash Anc Sci Life 34:121

van Bueren AL, Saraf A, Martens EC, Dijkhuizen L (2015) Differential metabolism of exopolysaccharides from probiotic Lactobacilli by the human gut symbiont Bacteroides thetaiotaomicron. Appl Environ Microbiol 81:3973-3983

Webster GF (2014) Inflammation in acne. In: Zouboulis CC, Katsambas A, Kligman AM (eds) Pathogenesis and treatment of acne and Rosacea. Springer Berlin Heidelberg 